\title{
Doing Business In..: A Class Exercise For International Accounting
}

Presha E. Neidermeyer, Ph.D., CPA, West Virginia University, USA

\begin{abstract}
International accounting is taught in the curriculum of about one-third of the largest institutions in the US. Within the context of this course, many instructors will attempt to cover a diverse array of business topics while integrating financial reporting standards worldwide. This breadth of topics is frequently challenging in obtaining a cohesive set of knowledge for the enrolled students. The use of a research paper documenting the business practices within a particular country and the subsequent presentation to either the international accounting class or preferably a larger audience can serve as a tool for organizing students' understanding of the breadth of the material and having individual students present a deeper depth of understanding within the selected country.
\end{abstract}

Keywords: International accounting, class exercise, term papers, student competency

\section{INTRODUCTION}

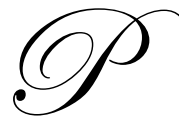

rofessors of international accounting have been increasingly called upon to integrate considerable amounts of materials into their courses over the past several years. The increasing acceptance of International Financial Reporting Standards (IFRS) worldwide has required substantial rewriting of the curriculum to include coverage of these financial regulations to the pre-existing broader accounting and general business topics within the course. It is likely that even more emphasis will be placed on the integration of IFRS into the accounting curriculum will come about as the US ponders a potential move from US GAAP to these standards within the next several years. ${ }^{1}$ The potential problem with these changing standards will occur if instructors move to solely covering these financial standards to the detriment of the larger and more complex issues such as culture including the historical background against which standards developed. These issues, while perhaps more illusive to students are critically important in interpreting the manner in which business people will interpret and use or in the case of accountants, process and integrate accounting information. Without such coverage the idea that a unified set of financial reporting requirements will produce a completely consistent set of financial outcomes will not be challenged as it should be. Accountants who do not recognize this important fact will not be aware that individuals raised in different environments may process the same information differently leading to divergent outcomes, likewise financial statement users may fail to recognize the same issue.

\section{A SUGGESTED CLASS EXERCISE}

Since coverage of divergent cultures is suggested and time is limited, a class exercise involving the students in presenting various national business practices provides an opportunity to introduce the ideas of culture and allow a deeper discussion of selected countries practices. The presenters can compare and contrast selected business practices leading to discussion of why these differences may have developed over time and how they impact

\footnotetext{
${ }^{1}$ The timeframe for movement to IFRS has been set from 2014-2016 with early adoption possible for large US firms whose competitors are reporting using IFRS. The decision as to whether to pursue this timeframe will be concluded in 2011 by the US Securities and Exchange Commission.
} 
individuals in the business environment from investors to entrepreneurs or managers. The suggested class exercise would involve an in-depth evaluation and presentation of the manner in which business is done in a selected country. The requirements for the exercise would be to document all relevant aspects of the country under investigation. The author suggests that students integrate the following into their paper. A short discussion of the reasoning behind each of these items follows.

\section{Topical Paper Requirements:}

- $\quad$ Historical background of the country under investigation

- Including integration of discussion of culture and demographic makeup of the country

- $\quad$ Economic and Political Climate

$\circ$ including the current status of the economy and privatization of formerly state held enterprises where appropriate

- $\quad$ Legal System

$\circ$ Including types of business models allowed for entry into the market

- $\quad$ Infrastructure

- Trading Partners

Within the context of their 8-20 page papers, students are required to complete a discussion on a minimum of the points listed above.

\section{Historical development}

A relatively short historical discussion of the country under investigation is the starting point to understanding the environment of the country. Without such a discussion the referencing of the manner historic evolution, the current business setting loses its flavor as one of evolutionary as compared to a dynamic system. For example, the current status of the business environment in Eastern Europe is highly influenced by the socialist backdrop against which regulated not only business but also most of society in these countries. To ignore that history is to lose all frame of reference as to the manner in which most of the older adult population was educated and raised and in which they operated for a long period of time. This has had long lasting impacts for the transition to capitalism as it required not only a change in the business environment but a change in the mindset of the individuals involved, without such migration the business and legal evolution would not have been possible. Similarly within Australia and other former British colonies, many carryovers exist despite the lack of continuing British rule, we can see this in various aspects of life from something as innocuous as a love of cricket and tea to something as pervasive as infrastructure (driving on the left side of the road) or the legal system that continues in the country. The historical background of the country gives the context and the flavor of the current business environment and helps to predict how things will move in the immediate future for the country as radical changes from historical development are not normal within either physical or man-made ecosystems. Ideally the student will have a short discussion of the major historical events within a country and will also provide these events in a timeline to allow a more linear evaluation by readers of the development of the country.

Demographic consideration and discussion is necessary, given the importance of the types of individuals available to both be served by the governments and be available as employees or entrepreneurs within the system. The development of the nation is strongly influenced by demographics on issues such as the educational system available to its citizenry, the social cohesiveness of the population, gender consideration and income levels. For example, a well-educated population provides a better base workforce for businesses who are not required to provide the same level of base education in a service based economy. Likewise, a strong middle class allows for significant investment to be made since governments are not required to provide the same level of public assistance (in terms of the percentage of the population requiring such assistance) as would occur in a country with a weaker middle and upper class. Finally within this section a listing of cultural values and taboos should be included. Students can reference what type of values a culture has by evaluating and discussing Hofstede's cultural dimensions and the placement of the selected country within the global context. Cultural eccentricities and other important factors might include the importance of relationships rather than low cost providers in Asia or the fact that business meetings should be held at the appointed time in Germany but not necessarily Central or South America. 


\section{Socio-economic events/developments}

The second topical discussion should be of the current economic and political environment. This should proceed naturally from the historical evaluation. An analysis of the current political parties and their impact on the business regulations and practices should be included. These talking points would include current political movements and leanings such as the importance of various political parties who might influence the way in which business were to be conducted in a particular country. For example, the current trend in Russia back toward political domination by the communist party or within the US the shift from a Republican to a Democratic presidency and the changes that such a change might imply. Likewise, major shifts in governments such as the change from communism to capitalism (or lightening of regulations) would need to be included and explicitly discussed as occurred in the former Eastern Europe countries or China. At present, students would be expected to include the stimulus programs that are being introduced to attempt to move the economy of a particular country forward in the midst of the world financial crisis currently being experienced and the manner in which these packages are proceeding. The current policy discussion would include fiscal policy as well as the amount of public debt.

\section{Legal systems}

A short discussion of the legal system will emanate from the political system. Rather than a complete history for law and society, to students are tasked with integration of the legal system with the business environment. Therefore, a short analysis of taxation, employment law, intellectual property and business law should be included. More detailed readings on all these topics in a reference list should be included but are not within the scope of the assignment for the class at hand.

\section{Infrastructure}

No discussion of a country would be complete without a discussion of the infrastructure available to businesses and individuals. The transportation system and telecommunications systems are critically important to the success of enterprises. The lack of such systems within many countries of Africa leads to a lack of potential foreign investment and the difficulty in getting goods and services provided in the hinterlands of various countries. Likewise, good transportation systems or potentials transportation systems lead to foreign investment within a country, for example the geographic placement of Bulgaria with a seaport and connections to Western European countries has led to the construction of highway systems by German and other foreign firms.

\section{Growth Industries}

To the extent that there are dedicated industries in which a country is attempting to compete these should be both noted and discussed. India's semi-recent decision to increase the emphasis it places on training individuals to be competitive in engineering and technology would be an example of this type of movement by a country.

\section{Trade}

Within the report either in the historical development section or a stand-along section, students should note the major trading partners and the magnitude of such imports and exports in financial terms with the country.

\section{PRESENTATION}

In addition to completing the aforementioned written report, students should present the material to the other enrolled students as the starting point to the discussion of the between country differences. The presentations should begin with a 10 minute discussion of each of the points mentioned above and concluded with all students who have done a report on a particular country finishing with a compare and contrast the various countries. Instructors should be encouraged to attempt to spread the coverage of various countries to those that are historically and economically divergent. Such action will lead to a more interesting class discussion with consideration country variation. 


\section{CONCLUSION}

The use of a research paper to illustrate the manner in which to do business in a particular country can serve as a starting point for introducing cultural and country-wide differences in an international accounting course. The coverage of these topics is important to the development of the student's understanding of the global business environment in which she will be operating.

\section{AUTHOR INFORMATION}

Presha E. Neidermeyer, Ph.D., CPA is an Associate Professor of Accounting in West Virginia University's College of Business and Economics. Her research specialty focuses on emerging issues in accounting including culture and international financial reporting. She has is the co-editor of Work, Life and Family Imbalance: How to Level the Playing Field and is co-author of the forthcoming book, Use What You Have: Resolving the HIV/AIDS Pandemic from Xlibris Publishing.

\section{REFERENCES}

1. Bloom, B.S. 1956. Taxonomy of Educational Objectives: The Classification of Educational Goals: Handbook 1. New York: Longmans Green.

2. Greenlaw, S. 2006. Doing economics: A guide to understanding and carrying out economic research. Boston: Houghton Mifflin.

3. McGoldrick, KimMarie. 2008. Writing Requirements and Economic Research Opportunities in the Undergraduate Curriculum: Results from a Survey of Departmental Practices. Journal of Economic Education 39(3): 287-296.

4. McGoldrick, KimMarie. 2008. Doing Economics: Enhancing Skills through a Process-Oriented Senior Research Course. Journal of Economic Education 39(4): 342-356.

5. Moy, Ronald L. 1995. Business and research proposals in economics and finance courses. Journal of Education for Business 71: 37.

6. Siegfried, John H. 2001. Principles for a successful undergraduate economics honors program. Journal of Economic Education 32(2): 169-178. 